CREAT. MATH. INFORM.

Volume 25 (2016), No. 2,

Pages i - viii
Online version at https : //creative-mathematics. cunbm. utcluj.ro/

Print Edition: ISSN 1584 - 286X; Online Edition: ISSN 1843 - 441X

DOI: https://doi.org/10.37193/CMI.2016.02.01

\title{
Creative Mathematics and Informatics: Celebrating a quarter century of publication
}

\author{
VASILE BERINDE
}

ABSTRACT. In order to mark the 25th anniversary of the journal Creative Mathematics and Informatics, we give a brief account on the main facts on its evolution since the previous anniversary notice published 5 years ago [Berinde, V., Creative Mathematics and Informatics: Celebrating 20 years of publication, Creat. Math. Inform., 20 (2011), No. 2, i - vi].

\section{INTRODUCTION}

Under the current name, Creative Mathematics and Informatics was edited in the last 14 years, succeeding the earlier journal Lucrările Seminarului de Creativitate Matematică, that was founded 25 years ago. For a very short period of time (2003-2005, i.e., volumes 12, 13 and 14), the journal bore the intermediate shorter name Creative Mathematics. For more information on these historical details, we refer the reader to our anniversary article [5] (and also to [2] and [3], for those able to understand Romanian language).

The initial vision of a local journal written in Romanian and devoted to elementary mathematics (problem solving), didactics of mathematics as well as to history of mathematics, has in the meantime given way, starting with 2003, to a journal in which English is the only language accepted for submitted material.

Moreover, the initial ideal that this journal is open for faculty and students from Baia Mare University evolved step by step to a broader editorial policy that made the journal open to contributions of scholars all over the world.

At the time of CMI's founding, the field of journals accepting papers not only in elementary mathematics / problem solving but also in history of mathematics, included many printed or electronically journals that are still keeping the same profile.

Creative Mathematics and Informatics has, for better or worse, changed significantly its remit since the years it bears the new English name. It accepts not only papers in elementary mathematics (problem solving), didactics of mathematics as well as in history of mathematics, but also in higher mathematics and computer science, with a perspective to interdisciplinary works that involve in a significant amount mathematics and / or computer science, as its name clearly announces.

\section{CMI'S ON-LINE EDITORIAL SYSTEM}

I shall start by presenting what I am considering to be the main achievement of the reported period 2012-2016, i.e., the designing, testing and implementing of the autonomous on-line editorial submission system SEMN (http: / / semn . ubm. ro/ cmi /).

When designing SEMN for CMI (it has been simultaneously implemented for our journal Carpathian J. Math., see http://semn.ubm.ro/cjm/), I had the chance to profit from two different professional experiences:

Received: 15.04.2016. In revised form: 23.04.2016. Accepted: 28.04.2016

2010 Mathematics Subject Classification. 01A05, 01A61, 01A65, 01A70, 01A99 .

Key words and phrases. journal anniversary, geographic coverage, on-line editorial system, impact, visibility. 
- my early and rather long experience as a computer programmer in a Computer Office after graduating university;

- my experience as an invited editor or reviewer to various international journals published by important commercial Editors (Elsevier, Springer etc.) that were benefiting of a web editorial platform from long time ago.

In this way, I was able to design a minimal editorial system and submission system, called SEMN (from the first letters of the syntagm Sistem Editorial Minimal Neterminat), which has been designed, tested and implemented in 2011 and 2012 and started to be operational by the end of December, 2012.

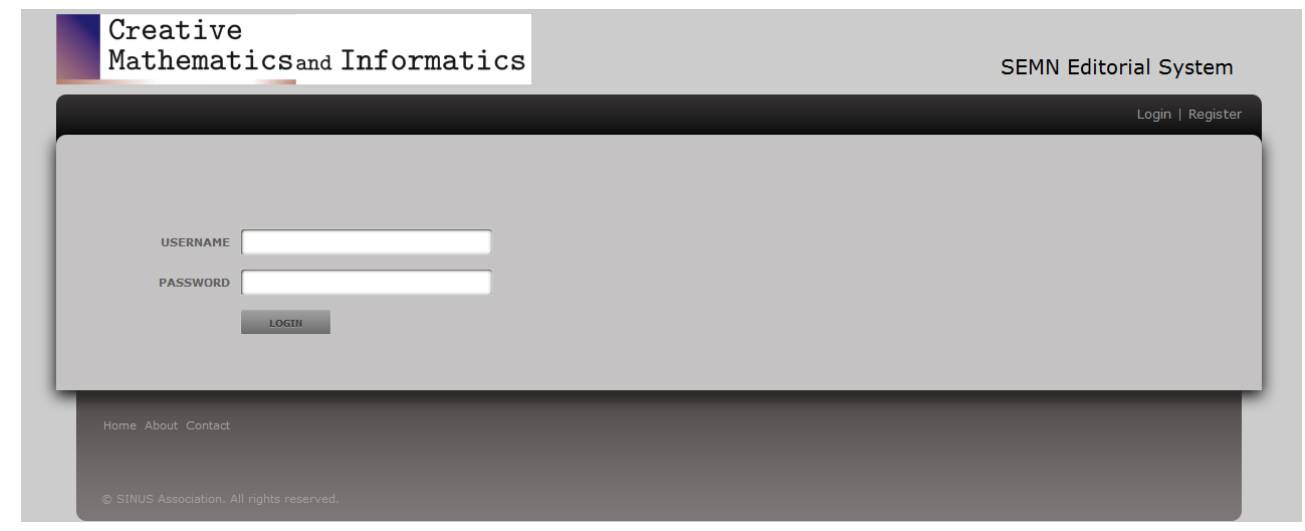

FIGURE 1. Print screen of the Editorial system SEMN login page

\section{EVOLUTION OF CMI IN THE PERIOD 2012-2016}

In order to have a view on the whole evolution of the journal with respect to the number of volumes, issues, number of published papers, number o pages per volume and in total, we present in the next three tables the corresponding information divided into three distinct periods of publication of the journal (1992-2001, 2002-2011, and 2012-2016).

This shows that journal has published more than 500 papers and almost 5000 pages in 25 years, which means on average more than 20 papers and almost 200 pages per volume.

It is a rather good record...

\begin{tabular}{|r|r|r|r|r|}
\hline Year & Volume & Issues & Papers & Pages \\
\hline $1991-1992$ & 1 & 1 & 12 & 138 \\
\hline $1992-1993$ & 2 & 1 & 18 & 178 \\
\hline $1993-1994$ & 3 & 1 & 14 & 144 \\
\hline $1994-1995$ & 4 & 1 & 20 & 158 \\
\hline $1995-1996$ & 5 & 1 & 22 & 142 \\
\hline $1996-1997$ & 6 & 1 & 12 & 128 \\
\hline $1997-1998$ & 7 & 1 & 17 & 144 \\
\hline $1998-1999$ & 8 & 1 & 19 & 162 \\
\hline $1999-2000$ & 9 & 1 & 23 & 184 \\
\hline 2001 & 10 & 1 & 25 & 234 \\
\hline & & & 182 & 1612 \\
\hline
\end{tabular}




\begin{tabular}{|r|r|r|r|r|}
\hline Year & Volume & Issues & Papers & Pages \\
\hline 2002 & 11 & 1 & 22 & 166 \\
\hline 2003 & 12 & 1 & 16 & 128 \\
\hline 2004 & 13 & 1 & 20 & 138 \\
\hline 2005 & 14 & 1 & 20 & 142 \\
\hline 2006 & 15 & 1 & 21 & 176 \\
\hline 2007 & 16 & 1 & 22 & 166 \\
\hline 2008 & 17 & $1,2,3$ & 71 & 554 \\
\hline 2009 & 18 & 1,2 & 31 & 228 \\
\hline 2010 & 19 & 1,2 & 31 & 234 \\
\hline 2011 & 20 & 1,2 & 29 & 206 \\
\hline & & & 183 & 2148 \\
\hline \hline Grand & Total & $(1991-2011)$ & 365 & 3760 \\
\hline
\end{tabular}

\begin{tabular}{|r|r|r|r|r|}
\hline Year & Volume No. & Issues / Vol. & Papers / Vol. & Pages / Vol. \\
\hline 2012 & 21 & 1,2 & 29 & 234 \\
\hline 2013 & 22 & 1,2 & 31 & 244 \\
\hline 2014 & 23 & 1,2 & 32 & 260 \\
\hline 2015 & 24 & 1,2 & 29 & 226 \\
\hline 2016 & 25 & 1,2 & 29 & 240 \\
\hline & Total & $(2012-2016)$ & 151 & 1210 \\
\hline \hline Grand & Total & $(1991-2016)$ & 516 & 4964 \\
\hline
\end{tabular}

\section{Geographical coverage}

Creative Mathematics and Informatics has a good geographical coverage with respect to both composition of the Editorial Board and authorship. In what concerns the geographical coverage by members of the Editorial Board, it looks quite nice: Bulgaria, Canada, Chile, China, Greece, Hungary, India, Japan, Moldova, Romania, Saudi Arabia, Senegal, Slovakia, South Africa, South Korea, Thailand, Turkey and U.S.A. are the countries of the editorial board members.

With respect to authors' geographical coverage, we can use the reports that Mathematical Reviews and Zentralblatt MATH databases provide, in order to present those who published in our journal for the period Creative Mathematics and Informatics has been reviewed (324 papers reviewed in the period 2004-2014 in Zentralblatt MATH; volumes 24 and 25 are not yet indexed): Berinde, Vasile (14 papers); Pop, Ovidiu T. (11); Bencze, Mihály; Bărbosu, Dan (9 papers each); Mortici, Cristinel; Cosma, Ovidiu (6 each); Fărcaş, Mircea D.; Ardelean, Gheorghe (5 papers each); Berinde, Zoiţa Mărioara; Aqzzouz, Belmesnaoui; Choban, Mitrofan M.; Gâta, Marieta; Lauran, Monica; Miclăuş, Dan; Păcurar, Mădălina; Pop, Adina; Pop, Vasile; Vescan, Andreea (4 papers each); Acu, Ana Maria; Balog, Laszlo; Bătineţu-Giurgiu, Dumitru M.; Bozântan, Andrei; Braica, Petru I.; Chiorean, Ioana; Danchev, Peter Vassilev; Darafsheh, Mohammad Reza; Horvat Marc, Andrei; Sass, Huba Istvan; Hussain, Sabir; Miclăuş, Gheorghe; Motogna, Simona-Claudia; Olatinwo, Memudu O.; Sass, Atilla Huba (3 papers each); Wu, Yu-Dong; Bagdasar, Ovidiu Dumitru; Bairac, Radu; Birou, Marius Mihai; Bojor, Florin; Borcut, Marin; Caldas, Miguel; Carpintero, Carlos R.; Changjian, Zhao; Chen, Chao-Ping; Elbour, Aziz; Filip, Diana Andrada; Furdui, Ovidiu C.; Gupta, Vijay; Guran, Liliana; Körtesi, Péter; Kovács, Gabriella; Kravecová, Daniela; Lambrou, Michael S.; Lazăr, Ioan-Alexandru; Lung, Rodica Ioana; Lupşa, Liana; Marinoiu, Cristian; Minculete, Nicuşor; Mingzhe, Gao; Mohammadyari, 
R.; Nageswara Rao, Sabbavarapu; Neamţiu, Luciana; Omerspahić, Alma; Omolehin, J.O.; Pârv, Bazil; Petric, Mihaela Ancuţa; Pişcoran, Laurian-Ioan; Pop, Maria S.; Rajesh, Neelamegarajan; Rosas, Ennis R.; Sabo, Cosmin; Şerban, Camelia; Şerban, Gabriela; Sîntămărian, Alina; Taşcu, Ioana; Tekcan, Ahmet; Țicală, Cristina; Toader, Cezar; Toader, Gheorghe; Toderean, Gavril; Vălcan, Dumitru; Vernescu, Andrei D.; Wang, Zhi-Gang (2 papers each); Zhang, Zhi-Hua; Abbas, Mujahid; Aboutafail, Othman; Abrudan, Horea F.; Acu, Dumitru; Adeniran, John Olusola; Al-Omari, Aiman; Al-Sharif, Sh.; Ali, Basit; Alomari, Mohammad Wajeeh; Aminpour, Abdol Mohammad; Andrejiová, Miriam; Andrica, Dorin; Andrica, Teodora; Aral, Ali; Arslandogan, N. Umut; Atanasiu, Virginia; Awan, Muhammad Uzair (1 paper each), ...

Now, using the same Zentralblatt MATH database reports, we can show the number of papers published on certain subjects (according to Mathematics Subject Classification 2010) the journal covered in the indexed period:

- 42 papers each subject: Real functions (26-XX); General topology (54-XX)

- 36 papers: Approximation and expansions (41-XX)

- 33 papers: Operator theory (47-XX)

- 30 papers: Computer science $(68-X X)$

- 25 papers: Numerical analysis $(65-X X)$

- 15 papers each: Combinatorics (05-XX); Sequences, series, summability (40-XX)

- 14 papers: Geometry (51-XX)

- 13 papers each subject: Ordinary differential equations (ODE) (34-XX); Game theory, economics, social and behavioral sciences (91-XX)

- 12 papers each subject: Number theory (11-XX); Group theory and generalizations (20-XX)

- 11 papers each subject: Optimization (90-XX); Mathematics education (97-XX)

- 10 papers: Applications of mathematics to Biology and other natural sciences (92XX)

- 9 papers each subject: General mathematics (00-XX); Statistics (62-XX); Information and communication, circuits (94-XX)

- 8 papers: Associative rings and algebras (16-XX)

- 7 papers each subject: Special functions (33-XX); Partial differential equations (PDE) (35-XX); Functional analysis (46-XX); Probability theory and stochastic processes $(60-X X)$

- 5 papers each subject: History; biography (01-XX); Ordered structures (06-XX); Field theory and polynomials (12-XX); Functions of a complex variable (30-XX); Difference and functional equations (39-XX)

- 4 papers each subject: Linear and multilinear algebra; matrix theory (15-XX); Topological groups, Lie groups (22-XX)Fourier analysis (42-XX); Integral equations (45-XX); Calculus of variations and optimal control; optimization (49-XX); Systems theory; control (93-XX)

- 3 papers each subject: Dynamical systems and ergodic theory (37-XX); Differential geometry (53-XX); Global analysis, analysis on manifolds (58-XX); Mechanics of deformable solids (74-XX);

- 2 papers each subject: Mathematical logic (03-XX); Convex and discrete geometry (52-XX); Fluid mechanics (76-XX); Relativity and gravitational theory (83-XX)

- 1 paper each subject: General algebraic systems (08-XX); Commutative algebra (13-XX); Measure and integration (28-XX); Functions of several complex variables and analytic spaces (32-XX); Mechanics of particles and systems (70-XX); Astronomy and astrophysics (85-XX) 
If we now go to MathScinet database, we found 287 indexed papers that were published in Creative Mathematics and Informatics in the period 2003-2015 (only issue no. 1/2015 is already indexed), with the following distribution of articles per subjects.

- 50 papers: Operator theory (47-XX)

- 45 papers: General topology (54-XX)

- 40 papers: Approximation and expansions (41-XX)

- 38 papers: Real functions (26-XX)

- 27 papers: Numerical analysis $(65-X X)$

- 20 papers: Combinatorics (05-XX)

- 14 papers: Sequences, series, summability $(40-X X)$

- 13 papers each subject: Number theory (11-XX); Special functions (33-XX)

- 12 papers each subject: Geometry (51-XX); Group theory and generalizations (20$\mathrm{XX})$; Difference and functional equations $(39-\mathrm{XX})$

- 10 papers each subject: Computer science (68-XX); Ordinary differential equations (ODE) (34-XX)

- 7 papers each subject: Information and communication, circuits (94-XX); Functional analysis (46-XX)

- 6 papers each subject: Game theory, economics, social and behavioral sciences (91-XX); Optimization (90-XX); Applications of mathematics to Biology and other natural sciences (92-XX); Associative rings and algebras (16-XX); Partial differential equations (PDE) (35-XX)

- 5 papers each subject: Statistics (62-XX); Ordered structures (06-XX); Functions of a complex variable (30-XX); Differential geometry (53-XX)

- 4 papers each subject: History; biography (01-XX); Linear and multilinear algebra; matrix theory (15-XX); Fourier analysis (42-XX); Dynamical systems and ergodic theory (37-XX); Integral equations (45-XX)

- 3 papers each subject: Probability theory and stochastic processes (60-XX); Topological groups, Lie groups (22-XX); Mechanics of deformable solids (74-XX); Measure and integration (28-XX);

- 2 papers each subject: General mathematics (00-XX); Field theory and polynomials (12-XX); Calculus of variations and optimal control; optimization (49-XX); Systems theory; control (93-XX); Mathematical logic (03-XX); Convex and discrete geometry (52-XX); Fluid mechanics (76-XX); Mechanics of particles and systems (70-XX);

- 1 paper each subject: Global analysis, analysis on manifolds (58-XX); Relativity and gravitational theory (83-XX); General algebraic systems (08-XX); Commutative algebra (13-XX); Astronomy and astrophysics (85-XX).

\section{IMPACT AND VISIBILITY}

Now we want to present some data on the journal's impact in the mathematical community. As we have seen in the previous section, its visibility is ensured by the fact that the great majority (but not all) of the papers published in Creative Mathematics and Informatics are indexed / reffered in the most important mathematical databases: Mathematical Reviews (MathScinet), with a total 287 papers indexed and Zentralblatt MATH with a total of 324 papers indexed, and also in EBSCO.

Apart of this, the printed version of the journal is visible nationally and internationally in many university libraries, due to a mutual exchange. Here is a partial list of journals 
from abroad included in the exchange scheme: Annales Univ. Scientiarum Budapestinensis; Atti del Seminario e Fisico del Universita di Modena; ATTI della Societa dei Naturalisti E Matematici di Modena; Bul. Academiei de Ştiinţhe a Moldovei. Matematica; Computer Science J. of Moldova; Glasnik Matematicki; Ingenerare Revista Faculdad de Ingeneria Univ. Catolica de Valparaiso; La Gaceta de la Real Sociedad Matematica Espanola; Matematica, Fyzika, Informatika; Matematika Plus; Math. J. of Okayama Univ.; Math. Competitions; Math. J. of Toyama Univ.; Mathematique et Pedagogie; Mediterranean J. for Research in Math. Education; Memoirs on differential equations and mathematical physics Georgia; Sarajevo J. Math.; Sociedad Andaluza de Educacion Matematica Thales (Epsilon); Studia Scientiarum Mathematicarum Hungarica; Suma; Teaching Mathematics and Computer Science; TWMS J. of Pure and Appl. Math.; Appl. and Computational Math.; Bull. de la Societé Royale des Mathematiques; Cuadernos del Instituto de Matematica Beppo Levi; Mathematicae Notae; Libertas Mathematica; CIT etc.

But, what is more important is the fact that the electronic version of Creative Mathematics and Informatics is visible by any search engine on the internet. Its web page, http: / / creative-mathematics.ubm.ro, contains all published papers in the first 25 years of existence. However, for the most recent papers, only the Abstracts and References are free available, but the articles using the Open Access Option, are still fully available.

Now, in order to illustrate the impact of Creative Mathematics and Informatics we refer first Web of Science (ISI), where we can find the so-called ISI citations. The most cited papers published in Creative Mathematics and Informatics in WoS are the following ones.

(1) 18 citations: Radu, Cristina. Statistical approximation properties of Kantorovich operators based on q-integers. Creat. Math. Inform. 17 (2008), no. 2, 75-84.

(2) 17 citations: Berinde, Vasile; Păcurar, Mădălina. The role of the Pompeiu-Hausdorff metric in fixed point theory. Creat. Math. Inform. 22 (2013), no. 2, 143-150.

(3) 13 citations: Păcurar, Mădălina. Remark regarding two classes of almost contractions with unique fixed point. Creat. Math. Inform. 19 (2010), no. 2, 178-183.

(4) 6 citations: Berinde, Vasile. A new generalization of Euler's constant. Creat. Math. Inform. 18 (2009), no. 2, 123-128.

(5) 5 citations: Berinde, Vasile; Kovács, Gabriella. Stabilizing discrete dynamical systems by monotone Krasnoselskij type iterative schemes. Creat. Math. Inform. 17 (2008), no. 3, 298-307.

(6) 4 citations: Bărbosu, Dan. Two dimensional divided differences revisited. Creat. Math. Inform. 17 (2008), 1-7.

(7) 4 citations: Berinde, Vasile; Păcurar, Mădălina. Two elementary applications of some Prešić type fixed point theorems. Creat. Math. Inform. 20 (2011), no. 1, 32-42.

(8) 4 citations: Borcut, Marin. Tripled coincidence theorems for monotone mappings in partially ordered metric spaces. Creat. Math. Inform. 21 (2012), no. 2, 135-142.

(9) 4 citations: Özdemir, M. Emin; Set, Erhan; Alomari, Mohammad. Integral inequalities via several kinds of convexity. Creat. Math. Inform. 20 (2011), no. 1, 62-73.

(10) 3 citations: Berinde, Vasile; Choban, Mitrofan. Generalized distances and their associate metrics. Impact on fixed point theory. Creat. Math. Inform. 22 (2013), no. 1, 23-32.

(11) 2 citations: Choban, Mitrofan M. Fixed points for mappings defined on pseudometric spaces. Creat. Math. Inform. 22 (2013), no. 2, 173-184.

(12) 2 citations: Dalmanoglu, Özge; Dogru, Ogün. Statistical approximation properties of Kantorovich type q-MKZ operators. Creat. Math. Inform. 19 (2010), no. 1, 15-24. 
(13) 2 citations: Gupta, Vijay; Sharma, Honey. Statistical approximation by q-integrated Meyer-König-Zeller-Kantorovich operators. Creat. Math. Inform. 19 (2010), no. 1, $45-52$.

(14) 2 citations: Marinescu, Dan Ştefan; Monea, Mihai. Some remarks on the Krasnoselskij iterative method. Creat. Math. Inform. 22 (2013), no. 2, 199-206.

(15) 2 citations: Minculete, Nicussor. A refinement of the Kittaneh-Manasrah inequality. Creat. Math. Inform. 20 (2011), no. 2, 157-162.

(16) 2 citations: Pop, Ovidiu T. About $T_{m, s}(x)$ polynomials. Creat. Math. Inform. 15 (2006), 47-52.

(17) 2 citations: Pop, Petrică; Sabo, Cosmin; Sitar, Corina Pop; Crăciun, Marian V. Solving the generalized minimum spanning tree problem with simulated annealing. Creat. Math. Inform. 16 (2007), 42-53.

(18) 2 citations: Rafiq, Arif; Acu, Ana Maria. A new implicit iteration process for two strongly pseudocontractive mappings. Creat. Math. Inform. 21 (2012), no. 2, 197-201.

(19) 2 citations: Shang, Yilun. The natural connectivity of colored random graphs. Creat. Math. Inform. 20 (2011), no. 2, 197-202.

(20) 2 citations: Sîntămărian, Alina. A new proof for estimating the remainder of the alternating harmonic series. Creat. Math. Inform. 21 (2012), no. 2, 221-225.

Now, in order to illustrate the impact of Creative Mathematics and Informatics according to SCOPUS, we just give the list of the first five most cited papers published in Creative Mathematics and Informatics. As it can be seen, the figures do not differ essentially from the ones from WoS.

(1) 19 citations: Radu, Cristina. Statistical approximation properties of Kantorovich operators based on q-integers. Creat. Math. Inform. 17 (2008), no. 2, 75-84.

(2) 17 citations: Berinde, Vasile; Păcurar, Mădălina. The role of the Pompeiu-Hausdorff metric in fixed point theory. Creat. Math. Inform. 22 (2013), no. 2, 143-150.

(3) 14 citations: Păcurar, Mădălina. Remark regarding two classes of almost contractions with unique fixed point. Creat. Math. Inform. 19 (2010), no. 2, 178-183.

(4) 9 citations: Berinde, Vasile. A new generalization of Euler's constant. Creat. Math. Inform. 18 (2009), no. 2, 123-128.

(5) 4 citations: Berinde, Vasile; Kovács, Gabriella. Stabilizing discrete dynamical systems by monotone Krasnoselskij type iterative schemes. Creat. Math. Inform. 17 (2008), no. 3, 298-307.

\section{CONCLUSIONS}

For the coming period, the main challenge for the Editor-in-Chief is related to the possible indexing of the journal in SCOPUS and Web of Science (ISI).This would be a normal reward for the steadily increasing quality of the journal in all respects.

Since Creative Mathematics and Informatics is still published in both printed and electronic format, another major challenge is to cope with the printing costs and steadily increasing postal taxes for sending the journal copies to our few subscribers and to the many exchange library partners. This ensures the presence and visibility of our journal in the shelves of many university libraries across the world even though nowadays most of the journals that increased their size (some of them from two issues per volume to twelve issues per volume!) are only electronically published.

I would like to conclude by noting that since the publication of its first issue / volume of this journal in 1992, Creative Mathematics and Informatics has seen strong growth in both print circulation and recently in website usage, as its readership and reputation have steadily increased. 
The are many colleagues and collaborators to whom I am grateful for their contribution to the current publication of the journal. For the activities carried out in last five years, I would like to express my thanks especially to Dr. Andrei Horvat-Marc, who was doing most of the work for the electronic version of the journal, and to Monica Pop, who was the devoted technical editor of the journal.

I would like to end by saying that I am really proud of all that Creative Mathematics and Informatics has achieved over the 25 years and confidently look forward for its future.

Acknowledgements. The paper was written during the author's visit at Department of Mathematics and Statistics, King Fahd University of Petroleum and Minerals, Dhahran, Saudi Arabia, in the period April-May 2016. He gratefully thanks Dr. Al-Homidan, dean of College of Sciences, and Dr. Al-Attas, the Chairman of the Department of Mathematics and Statistics, for the excellent conditions they offered during the visit. The author would also like to acknowledge the support provided by the Deanship of Scientific Research at King Fahd University of Petroleum and Minerals for funding this work through the projects IN151014 and IN151017.

\section{REFERENCES}

[1] Ardelean, Gh., INDEX VOL. I-X. Lucrările Seminarului de Creativitate Matematică, Lucr. Semin. Creativ. Mat., 10 (2001), 225-232

[2] Berinde, V., Prefaţă la volumul I al Seminarului de Creativitate Matematică, Lucr. Semin. Creativ. Mat., 1 (1991-1992), i-ii

[3] Berinde, V., 10 ani de apariţie a revistei Lucrările Seminarului de Creativitate Matematică, Lucr. Semin. Creativ. Mat., 10 (2001), i-ii

[4] Berinde, V., Carpathian Journal of Mathematics: celebrating 25 years of publication of the new series, Carpathian J. Math., 31 (2015), No. 3, i-vi

[5] Berinde, V., Creative Mathematics and Informatics: Celebrating 20 years of publication, Creat. Math. Inform., 20 (2011), No. 2, i-vi

${ }^{1}$ Department of Mathematics and Computer SCience

NORTH UNIVERSITY CENTER AT BAIA MARE

TECHNiCAl UNIVERSITY OF ClUj-NAPOCA Victoriei 76, 430122 BAIA MARE Romania

Email address: vberinde@ubm. ro

2 Department of Mathematics and Statistics

King Fahd University of Petroleum and Minerals

DHAHRAN, SAUdi ARABIA

Email address: vasile.berinde@gmail.com 